\title{
Analysis of pressure waves observed in Sakurajima eruption movies
}

\author{
Akihiko Yokoo and Kazuhiro Ishihara \\ Sakurajima Volcano Research Center, Disaster Prevention Research Institute, Kyoto University, \\ 1722-19 Sakurajima-Yokoyamacho, Kagoshima 891-1419, Japan
}

(Received June 24, 2006; Revised November 14, 2006; Accepted November 16, 2006; Online published March 23, 2007)

\begin{abstract}
Four eruption movies of Sakurajima volcano taken in the 1980s are analyzed. Pressure waves associated with these eruptions are identified by changes in luminance using a new image processing method. Results of the processing determined the apparent speeds of these waves at approximately $342-574 \mathrm{~m} / \mathrm{s}$. Further, spatial characteristics of the pressure waves are quantitatively investigated to estimate the source conditions of volcanic explosions.
\end{abstract}

Key words: Sakurajima volcano, image processing, visualized pressure waves.

\section{Introduction}

Strong atmospheric pressure perturbation is known to be generated by an explosive volcanic eruption and propagates as sound and infrasound waves. These waves, which have been recorded by microphones and on microbarographs at numerous volcanoes worldwide (e.g., Kamo et al., 1994; Ripepe and Marchetti, 2002), are of importance in the understanding of source dynamics and/or the mechanism of volcanic explosions (Buckingham and Garcés, 1996; Vergniolle and Brandeis, 1996; Morrissey and Chouet, 1997).

Strong pressure waves are commonly visualized above the crater as a flashing arc, as first observed at Vesuvius by a change in the refractive index of air (Perret, 1912). A vulcanian eruption of Ngauruhoe in 1975 produced a temporal condensation cloud that was considered to correspond to the rarefaction phase of a shock wave (Nairn, 1976). At Sakurajima, the disappearance of a part of the preceding cloud caused by the compression phase has been captured by a TV camera (Ishihara, 1985).

Yokoo and Taniguchi (2004) recently developed a method to detect pressure waves from eruption movies using image processing. This image processing method identified pressure waves within the ash-laden plume at Aso volcano that were otherwise too weak to be recognized directly by the naked eye. The same method is applied here to old Sakurajima eruption movies to re-examine the characteristic properties of pressure waves.

\section{Movies Images of Sakurajima Eruptions}

Nearly 8000 explosive eruptions (vulcanian-type of eruptions) have been recorded at Sakurajima volcano in southern Kyushu, Japan since 1955. These eruptions are typically accompanied by strong air-shocks emitted by the outburst of a gas pocket beneath the crater (Ishihara, 1985). The general

Copyright (c) The Society of Geomagnetism and Earth, Planetary and Space Sciences (SGEPSS); The Seismological Society of Japan; The Volcanological Society of Japan; The Geodetic Society of Japan; The Japanese Society for Planetary Sciences; TERRAPUB waveform of air-shock observed from recordings by microphones is mainly composed of two phases: an impulsive compression phase lasting 0.6-1.5 $\mathrm{s}$ and a subsequent rarefaction phase with a longer duration (Iguchi and Ishihara, 1990; Garcés et al., 1999).

In the early 1980s, Sakurajima Volcano Observatory (SVO) installed a monitoring system for eruptions by combining a TV camera with seismometers (Fig. 1). This system succeeded in capturing visible waves through the clouds during explosive eruptions, the velocities of which were estimated to be $440-550 \mathrm{~m} / \mathrm{s}$ by tracing the disappearance position of the clouds (Ishihara, 1985).

Four eruption movies obtained by the monitoring system in the 1980 s are selected in this study (Table 1). All movies are of vulcanian-type eruptions accompanied by pressure waves of 90-320 Pa recorded on a microbarograph at Harutayama (HAR), $2.7 \mathrm{~km}$ from the summit (Fig. 1; Table 1).

An example of an eruption image (A23 eruption; Dec. $15,1982)$ is selected to explain the nature of the visualized pressure waves. Four snapshots with luminance profiles of this eruption taken at 1.0-s intervals are shown in Fig. 2. Before the eruption, white clouds existed just above the crater (1065-1440 m altitude; frame \#00 in Fig. 2). After $1.0 \mathrm{~s}$, parts of the clouds turned slightly darker (\#30), then became white in the upper part (\#60). The clouds quickly returned to their original appearance before eruption (\#90). Detailed characteristics of this phenomenon are described in the next section.

\section{Image Processing and Results}

Image processing of the four movies recorded on U-matic video tapes are converted to digital files with VGA-sized resolution $(640 \times 480 \mathrm{pix})$ and $30 \mathrm{fps}$. Image processing follows the method of Yokoo and Taniguchi (2004) in which the luminance data of the image is calculated by the following equation:

$$
Y=0.299 \times R+0.587 \times G+0.114 \times B,
$$

where, Luminance, $Y$, is an index of brightness on digital 
Table 1. Summary of results obtained from the movie image analysis

\begin{tabular}{lllllll}
\hline No. & Date \& Time & \multicolumn{1}{c}{$\begin{array}{l}P^{\mathrm{a}} \\
(\mathrm{Pa})\end{array}$} & $\begin{array}{l}V_{\text {comp }}{ }^{\mathrm{b}} \\
\mathrm{m} / \mathrm{s})\end{array}$ & $\begin{array}{l}V_{\text {rare }} \mathrm{b} \\
(\mathrm{m} / \mathrm{s})\end{array}$ & $\begin{array}{l}\lambda_{\text {comp }}{ }^{\mathrm{c}} \\
(\mathrm{m})\end{array}$ & $\begin{array}{l}\lambda_{\text {rare }}{ }^{\mathrm{c}} \\
(\mathrm{m})\end{array}$ \\
\hline A05 & $1982 / 05 / 2311: 28$ & 140 & & $574( \pm 21)$ & & $>280$ \\
A09 & $1982 / 06 / 0711: 26$ & 90 & $342( \pm 28)$ & & 150 & $>390$ \\
A23 & $1982 / 12 / 1511: 25$ & 110 & $459( \pm 22)$ & $464( \pm 14)$ & 175 & $>210$ \\
A83 & $1987 / 12 / 0810: 40$ & 320 & & $514( \pm 14)$ & & \\
\hline
\end{tabular}

${ }^{a}$ Amplitude of pressure wave recorded at HAR, $2.7 \mathrm{~km}$ from the summit crater.

${ }^{b}$ Propagation speed of compression and rarefaction phases of pressure wave.

${ }^{c}$ Length of compression and rarefaction phases of pressure wave.

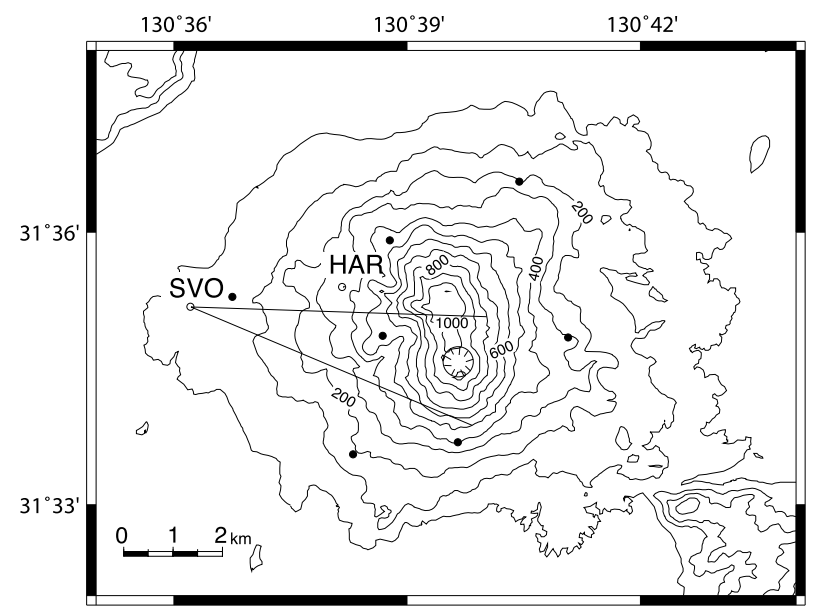

Fig. 1. Sketch map of Sakurajima volcano with 100-m contours. SVO and HAR (open circles) denote the locations of a TV camera and a microbarograph, respectively. Solid circles denote the seismic stations. The area between the two lines indicates the field of view of the movie image of the A23 eruption, as shown in Fig. 2.

images and is calculated from $R, G$ and $B$ color data for each pixel (Richard, 1977; eq. (1.38) of Plataniotis and Venetsanopoulos, 2000). This index corresponds to the gray scale of the image. $R, G$ and $B$ data are 8-bit values for each; therefore, the range of $Y$ becomes $0-255$. Increases or decreases in $Y$ values show darker or brighter on the digital images, respectively.

To quantify the pressure wave visualized by image processing, a rectangular zone of 20-pix width is selected, as shown at the center of the frame \#00 (Fig. 2). Next, the mean luminance, $\bar{Y}$, for each horizontal line in this zone, which is an indicator of altitude, is calculated for each frame.

Resulting sequential changes in mean luminance at several altitudes (1100-1475 m) are shown in Fig. 3(a). Propagating pressure waves are recognized as the first dark and the subsequent bright changes in the images. This effect is particularly clear at altitudes of $1125-1425 \mathrm{~m}$ where the clouds existed before the eruption (Fig. 2). Temporal condensation clouds are also recognized as increasing in luminance at an altitude of $1450 \mathrm{~m}$ where no cloud existed before the eruption.

The luminance changes in an amplitude of the first dark portion is normalized and shifted to match the onset time, indicated by left-side arrows in Fig. 3(a). As a result of stacking the normalized changes, the duration of the dark portion is constrained to be about $0.4-0.5 \mathrm{~s}$ (Fig. 3(b)). On the other hand, the duration of the bright portion is 1.0$2.5 \mathrm{~s}$. The luminance change in the bright portion is a few times greater than that of the dark portion, making it easy to recognize the latter phase by the formation of condensation clouds on the time-sequenced images.

Also of note is that the differences between onset time of the dark portion and time of the brightest peak were fairly constant at $0.7-0.9 \mathrm{~s}$ (Fig. 3(b)). This finding suggests that the apparent speeds of the propagating pressure wave were of similar value. To verify this, these two times of changes in luminance are checked at every 5-8 $\mathrm{m}$ increase in altitude (Fig. 4). The velocities of the waves are estimated to be 459 $\mathrm{m} / \mathrm{s}( \pm 22 \mathrm{~m} / \mathrm{s})$ and $464 \mathrm{~m} / \mathrm{s}( \pm 14 \mathrm{~m} / \mathrm{s})$, respectively, both of which are greater than the speed of sound in air $(\sim 335 \mathrm{~m} / \mathrm{s})$.

Iguchi and Ishihara (1990) reported that duration of the compression phase observed at SVO $(5.5 \mathrm{~km}$ from the crater; Fig. 1) was 0.6-1.5 s with a much longer rarefaction phase. Image processing in the present study revealed a similar duration for the first dark portion of about 0.4$0.5 \mathrm{~s}$, with that of the following dark portion a few times longer. Considering that these changes occurred just above the crater, the dark and bright portions are thought to correspond to the compression and rarefaction phases of the pressure wave, respectively. Assuming that the visual appearance of the pressure wave was induced by a phase change of $\mathrm{H}_{2} \mathrm{O}$ with no time delay, the velocity of the compression phase of the pressure wave, $V_{\text {comp }}$ in Table 1 , is considered to be $459 \mathrm{~m} / \mathrm{s}$ and the representative velocity of rarefaction phases, $V_{\text {rare }}$, is $464 \mathrm{~m} / \mathrm{s}$.

The spatial dimension of the compression and rarefaction phases is estimated by a method that averages luminance data in the selected rectangular zone at the first frame (\#00), which is then subtracted from mean data estimated in subsequent frames. Resultant profiles of the luminance change at 5-frame intervals (1/6 s) are plotted in Fig. 5. The first dark portion and subsequent bright portion can be clearly seen to propagated upwards. The length of the compression phase, $\lambda_{\text {comp }}$, was approximately $175 \mathrm{~m}$, and that of the rarefaction phase, $\lambda_{\text {rare }}$, was $390 \mathrm{~m}$ or more.

Results of data processing for all four eruptions are summarized in Table 1. Apparent speeds of the pressure waves, $V_{\text {comp }}$ and $V_{\text {rare }}$, were greater than the sound velocity in air. However, all parameters could be determined only for the A23 eruption. In the cases of the A05 and A83 eruptions, only condensation clouds were distinguishable from luminance data (Fig. 6). In this case, the velocity and wavelength of the rarefaction phase of the pressure waves were 

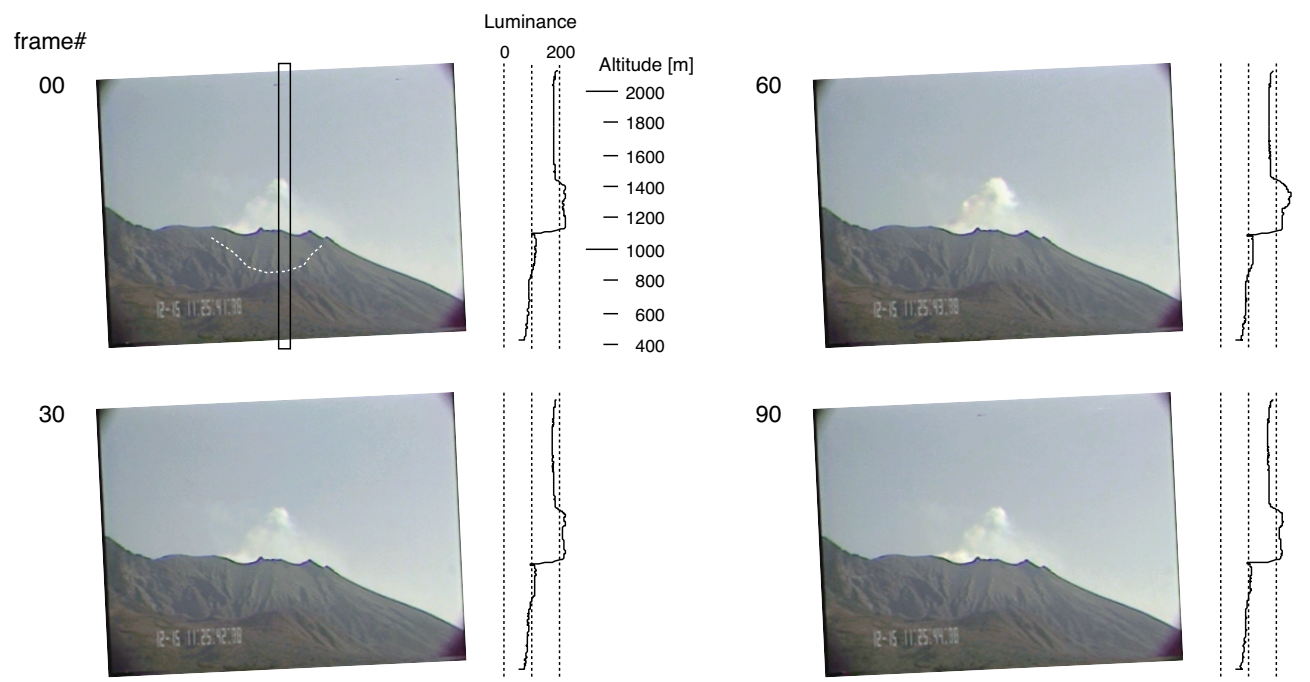

Fig. 2. Four snapshots of the A23 eruption at 1.0-s intervals (frames \#00, \#30, \#60 and \#90). Vertical luminance profiles along the rectangular zone, as shown in \#00, are also seen to the right of each snapshot. The white dashed line in \#00 indicates the profile of the summit crater based on the topographical map of 1981 created by the Geographical Survey Institute (altitude of crater bottom is $\sim 850 \mathrm{~m}$ ).

(a)

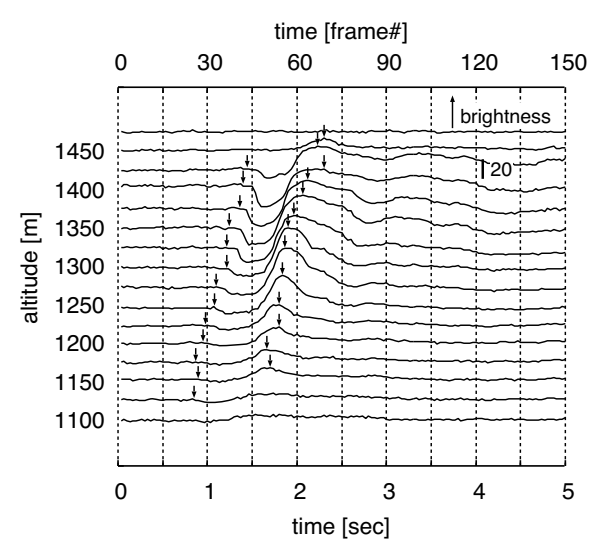

(b)

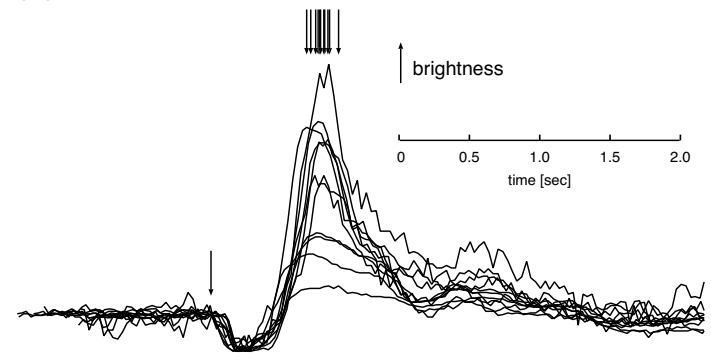

Fig. 3. (a) Luminance changes with time at several altitudes ranging from $1100-1475 \mathrm{~m}$. Increasing luminance or brightening is plotted upwards. Each arrow on the left side denotes the onset of the dark portion and that on the right denotes the time of highest luminance, or the brightest portion. (b) Eleven stacked luminance changes normalized to the change in the first dark portion (1150-1400 m). All downward arrows are at the same position of time in (a).

estimated. Only the values of the compression phase for the A09 eruption could be calculated.

\section{Discussion}

The time delay between the pressure wave and other eruption phenomena provides us with useful information on eruption dynamics (Ripepe et al., 2001, 2002). In the case

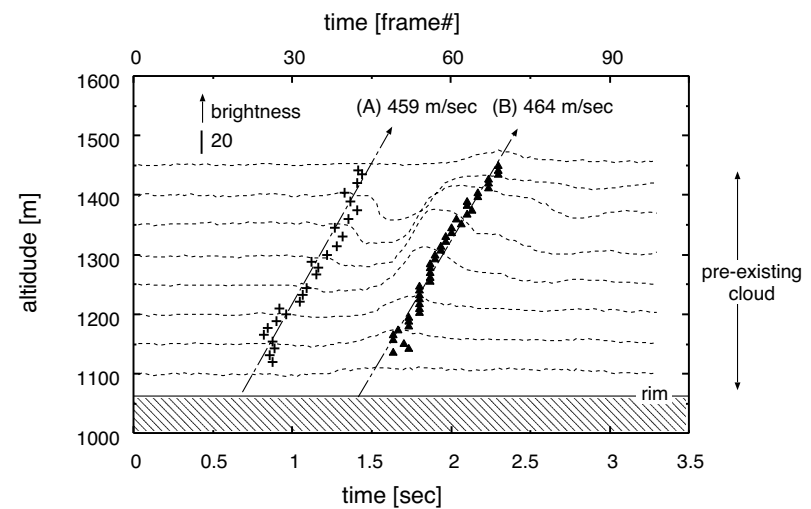

Fig. 4. Sequential relationship of (A) onset time of the dark portion and (B) time of the brightest peak at each altitude. Eight dotted lines represent sequential luminance changes at each altitude.

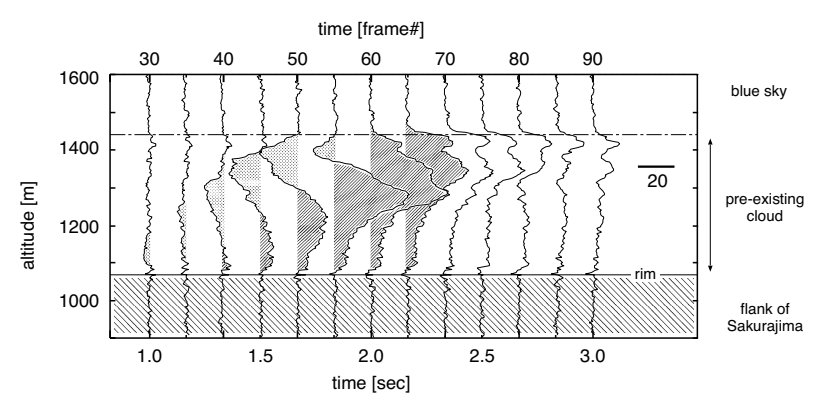

Fig. 5. Differences in luminance data over the time sequence. Plus values are shown to the right, indicating brightening.

of the A23 eruption, the pressure wave was emitted from the crater about $2.4 \mathrm{~s}$ or longer before the ejection of the volcanic cloud (Fig. 7). This time delay suggests that surface phenomena of a volcanic explosion are started by the outburst of a gas pocket just beneath the crater bottom (at the uppermost part of a magma conduit), then pyroclastic materials are ejected as a volcanic cloud from a deeper part 
(a)
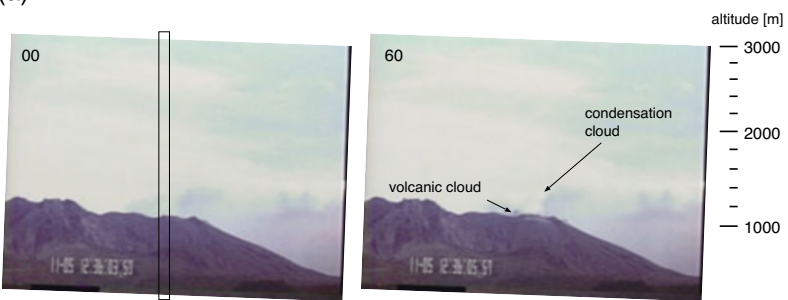

(b)

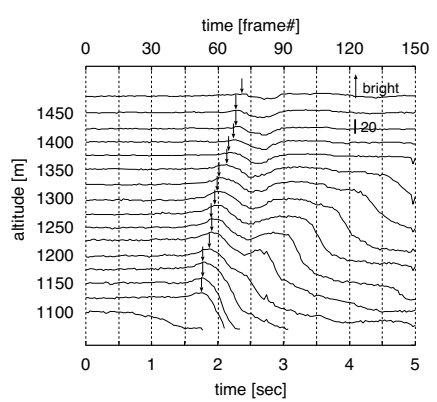

Fig. 6. (a) Images of A83 eruption (frames \#00 and \#60). (b) Sequential luminance changes at several altitudes with arrows indicating the brightest portions. Disturbance in the lower right is caused by a rising volcanic cloud.

(a)

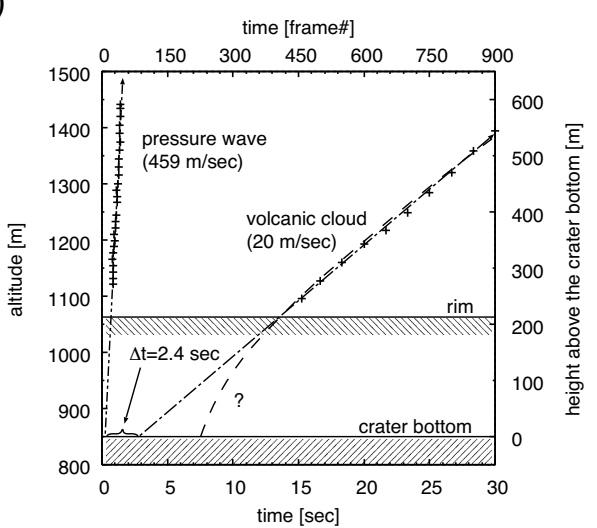

(b)

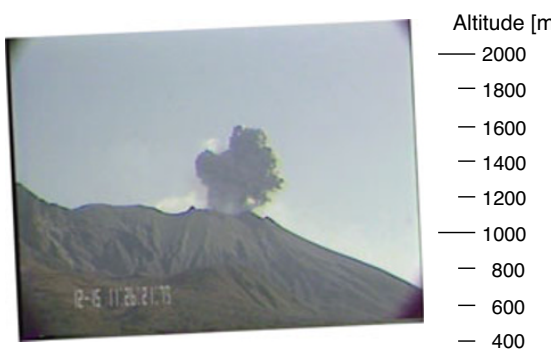

Fig. 7. (a) Relationship between propagating pressure wave and rising volcanic cloud over time for the A23 eruption. $\Delta t$ is minimum time delay of these two phenomena at the crater bottom. (b) Snapshot of the A23 volcanic cloud at frame \#1200.

of the conduit (Ishihara, 1985).

We attempt here to estimate the internal pressure and size of the gas pocket using a 1-D spherical explosion model that is characterized as an instantaneous rupture of a spherical vessel containing a high-pressurized gas (Sod, 1977; Saito and Glass, 1979). Velocities of pressure waves and pressure changes are calculated numerically and then compared with
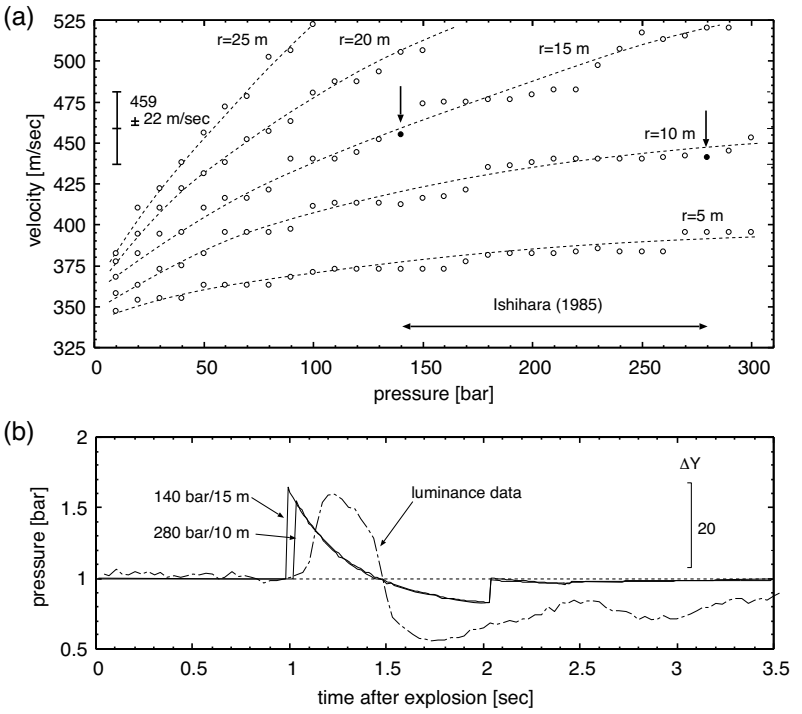

Fig. 8. (a) Relationship between internal pressure and mean velocity of pressure wave at a range of $250-600 \mathrm{~m}$ distance calculated from a 1D spherical explosion model. $r$ denotes the radius of the gas pocket. (b) Comparison between calculated waveforms of pressure waves at $550 \mathrm{~m}$ from the source and observed luminance change at $550 \mathrm{~m}$ above the bottom but plotted upside down (data equivalent to $1400 \mathrm{~m}$ altitude).

those of the luminance change derived from the images.

The 1-D basic equations for an inviscid, non-heatconducting, spherical-symmetric flow can be written in vector form as follows (Sod, 1977):

$$
\boldsymbol{U}_{t}+F(\boldsymbol{U})_{x}=-W(\boldsymbol{U})
$$

where,

$$
\begin{gathered}
\boldsymbol{U}=\left(\begin{array}{c}
\rho \\
m \\
e
\end{array}\right) \\
F(\boldsymbol{U})=\left(\begin{array}{c}
m \\
m^{2} / \rho+p \\
m(e+p) / \rho
\end{array}\right) \\
W(\boldsymbol{U})=(\alpha-1)\left(\begin{array}{c}
m / x \\
m^{2} / \rho x \\
m(e+p) / \rho x
\end{array}\right) .
\end{gathered}
$$

Here, $\rho$ is the density, $m$ is the momentum, $p$ is the pressure, $e$ is the energy per unit volume, $t$ is time, $x$ is the space co-ordinate of symmetry, and subscripts indicate differentiations. $\alpha$ is a constant which is equal to 3 for this spherical symmetry case. We may write $m$ and $e$ as

$$
\begin{gathered}
m=\rho u \\
e=\frac{p}{\gamma-1}+\frac{1}{2} \rho u^{2},
\end{gathered}
$$

where $u$ and $\gamma$ are the velocity and the ratio of specific heat, respectively. The gas pocket is assumed to be composed of $500^{\circ} \mathrm{C} \mathrm{H}_{2} \mathrm{O}$ vapor degassed from magma, and the atmosphere is air of $5^{\circ} \mathrm{C}$. The values of $\rho$ for both the gas pocket and outside the gas pocket are estimated using the equation of state for ideal gas: $p=\rho R T$. 
Based on the results of numerical calculation, the mean velocity of the pressure wave at $250-600 \mathrm{~m}$ distance from the crater bottom is determined from two parameters: internal pressure and radius of the gas pocket (Fig. 8(a)). This range of distance is equivalent to altitudes of 1100-1450 m, within which the waves of the A23 eruption are observed in movie images (Figs. 2 and 4). This relation indicates that if a source pressure is assumed to be 140-280 bars, as estimated from initial ejection speeds of ballistics basically according to Bernoulli's equation (Iguchi et al., 1983; Ishihara, 1985, 1990), then a radius of $10-15 \mathrm{~m}$ would be required. This estimated radius is comparable to the size of a red-growing part in the lava dome that disappears after the explosion. It is also consistent with the size of the pressure source estimated from ground deformation data (Ishihara, 1990).

Pressure waveforms at a distance of $550 \mathrm{~m}$ from the crater bottom for the two cases of source conditions are calculated (Fig. 8(b); internal pressure and radius are 140 bar and $15 \mathrm{~m}$, and $280 \mathrm{bar}$ and $10 \mathrm{~m}$, respectively). Observed luminance change at the same distance, corresponding to an altitude of $1400 \mathrm{~m}$, is also illustrated in the same figure using a representative actual pressure wave. Comparing the pressure waveform with the luminance change, the calculated duration of the compression phase of the wave is found to almost coincide with that of the luminance change. In contrast, the subsequent rarefaction phase does not show such good agreement with that of luminance. We believe this discrepancy is due primarily to the simplicity of the explosion model used here; for example, the model does not account for viscous property of the air through which the waves pass. Nevertheless, combining digital image processing with numerical simulations of propagating pressure waves appears to be a promising tool for the the evaluation of the source conditions of volcanic explosions.

\section{Concluding Remarks}

We re-examined eruption movies of Sakurajima volcano using an image processing method that allows for the easy identification of propagating atmospheric pressure waves from changes in luminance. Characteristic features of the waves excited by the explosions, such as velocity, were derived quantitatively. The apparent propagating speeds of the identified pressure waves were greater than the sound velocity of air (342-574 m/s). A spatial scale of the compression phase was about $150 \mathrm{~m}$ and that of the rarefaction phase was a few times longer. Such results from movie images may lead to a better understanding of the source conditions of volcanic explosions when combined with numerical simulation of pressure wave dynamics.

Acknowledgments. We thank all staff members of Sakurajima Volcano Research Center for their support, especially M. Iguchi for constructive comments. T. Saito provided the code of RCM and helpful suggestions. The manuscript has benefited greatly from critical readings by M. Morrissey and M. Ripepe. This study was supported in part by the Japanese Ministry of Education, Culture, Sports, Science and Technology (MEXT) 21st Century COE program for DPRI, Kyoto University (\#14219301, Program Leader: Y. Kawata).

\section{References}

Buckingham, M. J. and M. A. Garcés, Canonical model of volcano acoustics, J. Geophys. Res., 101, 8129-8151, 1996.

Garcés, M. A., M. Iguchi, K. Ishihara, M. Morrissey, Y. Sudo, and T. Tsutsui, Infrasonic precursors to a Vulcanian eruption at Sakurajima Volcano, Japan, Geophys. Res. Lett., 26, 2537-2540, 1999.

Iguchi, M., K. Ishihara, and K. Kamo, On ejection velocity and pressure of volcanic explosion reduced from photo-trajectory of volcanic bombs, Ann. Disas. Prev. Res. Inst., Kyoto Univ., 26B-1, 1-13, 1983.

Iguchi, M. and K. Ishihara, Comparison of earthquakes and air-shocks accompanied with explosive eruptions at Sakurajima and Suwanosejima volcanoes, Ann. Disas. Prev. Res. Inst., Kyoto Univ., 33B-1, 1-12, 1990 (in Japanese with English abstract).

Ishihara, K., Dynamic analysis of volcanic explosion, J. Geodyn., 3, 327349, 1985.

Ishihara, K., Pressure sources and induced ground deformation associated with explosive eruptions at an andesitic volcano: Sakurajima volcano, Japan, in Magma Transport and Storage, edited by M. P. Ryan, pp. 336356, 1990.

Kamo, K., K. Ishihara, and M. Tahira, Infrasonic and seismic detection of explosive eruptions at Sakurajima volcano, Japan, and the PEGASASVE early-warning system, in Volcanic Ash and Aviation Safety, Proceedings of the First Int Symposium on Volcanic Ash and Aviation Safety, edited by T. C. Casadevall, USGS Bull., 2047, 357-365 1994.

Plataniotis, K. N. and A. N. Venetsanopoulos, Color Image Processing and Applications, 330 pp., Springer-Verlag, Berlin, 2000

Morrissey, M. M. and B. A. Chouet, Burst conditions of explosive volcanic eruptions recorded on microbarographs, Science, 275, 1290-1293, 1997.

Nairn, I. A., Atmospheric shock waves and condensation clouds from Ngauruhoe explosion eruption, Nature, 259, 190-192, 1976.

Perret, A. F., The flashing arcs: A volcanic phenomenon, Am. J. Sci., 4, 329-333, 1912.

Richard, D. H., U.S. color television fundamentals-A review, IEEE Trans. Cons. Electron, CE-23, 467-478, 1977.

Ripepe, M. and E. Marchetti, Array tracking of infrasonic sources at Stromboli volcano, Geophys. Res. Lett., 29, 2076, doi:10.1029/ 2002GL015452, 2002.

Ripepe, M., S. Ciliberto, and M. D. Schiava, Time constraints for modeling source dynamics of volcanic explosions at Stromboli, J. Geophys. Res., 106, 8713-8727, 2001.

Ripepe, M., A. J. L. Harris, and R. Carniel, Thermal, seismic and infrasonic evidences of variable degassing rates at Stromboli volcano, J. Volcanol. Geotherm. Res., 118, 285-297, 2002.

Saito, T. and I. I. Glass, Application of Random-Choice Method to problems in shock and detonation-wave dynamics, UTIAS Report, 240, 128, 1979.

Sod, G. A., A numerical study of a converging cylindrical shock, J. Fluid Mech., 83, 785-794, 1977.

Vergniolle, S. and G. Brandeis, Strombolian explosions 1. A large bubble breaking at the surface of a lava column as a source of sound, J. Geophys. Res., 101, 20433-20447, 1996.

Yokoo, A. and H. Taniguchi, Application of video image processing to detect volcanic pressure waves: A case study on image archives of Aso Volcano, Japan, Geophys. Res. Lett., 31, L20604, doi:10.1029/ 2004GL021183, 2004.

A. Yokoo (e-mail: yokoo@svo.dpri.kyoto-u.ac.jp) and K. Ishihara 